\title{
Implementation and Outcomes of Commercial Disease Management Programs in the United States: The Disease Management Outcomes Consolidation Survey
}

\author{
KAREN FITZNER, Ph.D., ${ }^{1}$ KATHE FOX, Ph.D., ${ }^{2}$ JOSEPH SCHMIDT, B.Sc., ${ }^{2}$ \\ MARK ROBERTS, Ph.D., ${ }^{3}$ DONNA RINDRESS, Ph.D., ${ }^{3}$ and JOEL HAY, Ph.D. ${ }^{4}$
}

\begin{abstract}
Despite widespread adoption of disease management (DM) programs by US health plans, gaps remain in the evidence for their benefit. The Disease Management Outcomes Consolidation Survey was designed to gather data on DM programs for commercial health plans, to assess program success and DM effectiveness. The questionnaire was mailed to 292 appropriate health plan contacts; 26 plans covering more than 14 million commercial members completed and returned the survey. Respondents reported that DM plays a significant and increasing role in their organizations. Key reasons for adopting DM were improving clinical outcomes, reducing medical costs and utilization, and improving member satisfaction. More respondents were highly satisfied with clinical results than with utilization or cost outcomes of their programs $(46 \%, 17 \%$, and $13 \%$, respectively). Detailed results were analyzed for 57 DM programs with over 230,000 enrollees. Most responding plans offered DM programs for diabetes and asthma, with return on investment (ROI) ranging from 0.16:1 to 4:1. Weighted by number of enrollees per DM program, average ROI was $2.56: 1$ for asthma $(n=1,136$ enrollees) and 1.98:1 for diabetes $(n=25,364)$. Most (but not all) respondents reported reduced hospital admissions, increasing rates of preventive care, and improved clinical measures. Few respondents provided detailed information about DM programs for other medical conditions, but most that did reported positive outcomes. Lack of standardized methodology was identified as a major barrier to in-house program evaluation. Although low response rate precluded drawing many general conclusions, a clear need emerged for more rigorous evaluation methods and greater standardization of outcomes measurement. (Disease Management 2005;8:253-264)
\end{abstract}

\section{INTRODUCTION}

D ISEASE MANAGEMENT (DM) programs are coordinated health care interventions for medical conditions in which patient self-care behaviors can play an important role. ${ }^{1}$ Specific populations are identified for enrollment in programs in which patients are monitored for deviations from evidence-based care or symptoms indicative of worsening health. ${ }^{2} \mathrm{DM}$

\footnotetext{
${ }^{1}$ Disease Management Association of America, Washington, D.C.

${ }^{2}$ Thomson Medstat, Ann Arbor, Michigan.

${ }^{3}$ BioMedCom Consultants inc., Montreal, QC, Canada.

${ }^{4}$ Department of Pharmaceutical Economics and Policy, University of Southern California, Los Angeles, California.
} 
programs aim to prevent exacerbations and complications by contacting patients and sometimes their physicians to provide support (eg, self-management education) to improve patient self-management skills. ${ }^{1,2}$

In addition to improving clinical outcomes and patient quality of life, an objective of DM programs of great importance to health plans and employers is to improve health care quality and control costs, for example by avoiding hospitalization. ${ }^{2}$ Although positive clinical outcomes of DM programs have been demonstrated in several studies, ${ }^{3}$ the economic benefit and financial return on investment (ROI) of DM programs have been challenged. On the basis of an analysis of the peer-reviewed literature of DM programs for congestive heart failure $(\mathrm{CHF})$, coronary artery disease (CAD) and diabetes, the US Congressional Budget Office (CBO) reported in October 2004 that there was insufficient evidence to conclude that DM programs reduce overall health care costs. ${ }^{4} \mathrm{Al}$ though the research methodology employed by the $\mathrm{CBO}$ to reach this conclusion has been questioned, ${ }^{5}$ another recent systematic literature review also found few studies had demonstrated significant cost savings for DM programs. ${ }^{3}$

The databases of commercial health plans that offer DM programs could help to fill the information gap on financial outcomes. Many DM programs are proprietary, and it has been suggested that more is known about costs for DM programs than has been published or released into the public domain. ${ }^{6}$ Furthermore, commercial health care organizations possess a wealth of other data on clinical and utilization outcomes, which could provide a more comprehensive understanding of the value of DM programs.

To capture information from health plans and other sources about DM programs and their outcomes, in 2004 the Disease Management Association of America (DMAA) launched the Disease Management Outcomes Consolidation Project. Components of the project were a comprehensive catalog of the published literature and unpublished reports, ${ }^{7}$ and a survey of health plans providing DM programs to commercial members, conducted by a qualified independent contractor (Medstat). The objectives of the survey were to allow comparison of results between different programs, and to serve as a resource for DMAA and its members to respond to government agencies, employers, and others who request evidence of the effectiveness of DM. Survey results are potentially valuable because they capture the experience of experts in commercial health plans who may not normally publish their opinions or the outcomes of their DM programs.

\section{MATERIALS AND METHODS}

\section{Survey design}

The Outcomes Consolidation Survey instrument was designed to record descriptions of health plan DM programs and associated clinical and economic outcomes. A preliminary Web-based version of the survey (DMAA Outcomes Collection Survey) was designed by the DMAA Quality and Research Committee and pilot-tested in 2003, targeting private US health insurance plans. This pilot survey was completed by 27 respondents with responsibility for DM program development or implementation within their organizations. The pilot survey requested details of DM program development, operational components, enrollment, longevity and outcomes. Additional items asked health plans to identify their rationale for offering DM programs, future program development priorities, barriers to program expansion, and use of the Internet. Respondents also rated their satisfaction with DM programs, the success of specific program components, and the importance of their DM programs to current and prospective customers. In collaboration with the DMAA Quality and Research Committee and the DMAA Outcomes Consolidation Steering Committee, Medstat used results of the 2003 pilot survey to refine the questionnaire. A revised version was sent to five health plans for pilot-testing, three of which responded. The survey was subsequently evaluated and refined by a Delphi panel of 15 national experts before production of the final version for the 2004 study.

The Outcomes Consolidation Survey instrument was distributed and returned by mail. The survey consisted of the following eight sections: organization description; DM approach; current DM programs for commercial members; DM 
program tools; DM program outcomes overview (a general assessment of program success); specific results from DM evaluations; DM programs and employer customers; and future planning for DM. Specific questions in each section are described in Results.

Responses were elicited in different ways due to the diverse nature of the topics. Questions required either Yes/No answers, numerical responses, ranking of a series of items, or selection of a grade on a four- or five-point Likert scale. Likert scales were anchored at extremes such as "strongly agree" and "strongly disagree," or "unimportant" and "very important." One five-part question regarding specific results from DM evaluations required freeform text responses.

\section{Subjects}

The Outcomes Consolidation Survey targeted US health plans covering commercial members. Directors of Disease Management were the preferred contacts within each plan, followed by Chief Executive Officers or Chief Medical Officers. Respondents were requested to consider in their responses all enrollees for whom their plan was the primary health care payer, which could potentially include some Medicare-eligible members over age 65 years. National plans offering multiple DM programs in different locations were invited to request additional copies of the survey to complete for different locations (eg, on a state-by-state basis).

The survey was mailed by DMAA on July 1 , 2004 to 702 health plan contacts compiled from a list of 90 DMAA members, 41 Medstat contacts, and an additional 571 contacts from the Managed Care Directory (Dorland Healthcare Information). The list was processed to prevent duplication and ensure that only one contact per organization was targeted. Reminder postcards were sent to all contacts two weeks later. Twenty-two surveys were returned as undeliverable. A research assistant subsequently attempted to contact all survey recipients by telephone, and determined that 410 contacts were either inaccurate or inappropriate (eg, dental plans). The remaining 292 recipients were offered free registration at the DMAA Disease Management Leadership Forum as incentive to complete and return the survey. Electronic copies of the survey were emailed to those recipients who requested them. Respondents returned completed, blinded surveys by mail to Medstat. Survey results were identified by unique identification number only to preserve respondent confidentiality. To permit follow-up, the survey included a coded identification sheet to be mailed to DMAA, but no one individual could see both the survey results and the contact names.

\section{Disease Management Outcomes Database}

Results of the Outcomes Consolidation Survey were processed by Medstat using a proprietary data entry and analysis tool. This database was designed to catalog information based on published literature, presentations and surveys completed by health plans, and stratified by medical condition and program operation (ie, in-house or outsourced). For the Outcomes Consolidation Survey results, the database recorded the research design and measures used by responding health plans to determine outcomes such as changes in clinical results, member satisfaction and financial outcomes.

\section{Statistical analysis}

Survey data were verified, aggregated in the Disease Management Outcomes Database, and analyzed to obtain summary statistics (percentages of respondents and means of numerical responses). Because this was a descriptive survey, no tests of statistical significance were performed. Missing responses were not imputed; instead, sample sizes were adjusted on a question-by-question basis when calculating summary statistics to account for missing responses. Respondents were not contacted for answers to missing items. Surveys were not excluded based on a threshold of acceptable missing data. DM program outcomes are reported in depth only for medical conditions with detailed responses from at least 10 health plans.

\section{RESULTS}

\section{Survey respondent characteristics}

Of the 292 appropriate health plan contacts who received the Outcomes Consolidation Sur- 
vey, 28 (9.6\%) completed and returned it. Two respondents did not indicate that they covered commercial members, and were excluded from further analysis. Of the remaining 26 respondents, 24 specified how many members (commercial or otherwise) were covered by their organizations and two did not answer this question. For the 24 respondents who did answer this question the average number of total health plan members was 666,459 . Eighteen of the 25 respondents $(72 \%)$ who specified the number of commercial enrollees covered by health maintenance organization (HMO), preferred provider organization/point-of-service (PPO/POS) or other (eg, indemnity) plans indicated that their organizations covered commercial members in more than one type of plan. A slim majority (51\%) of the $14,069,792$ reported commercial members were covered by PPO/POS plans, with $40 \%$ covered by HMO plans and $9 \%$ by other, unspecified plans. The average number of commercial members per plan was 266,959, 361,839, and 87,634 (medians: $106,904,59,800$, and 77,827$)$ for HMO $(n=21)$, PPO/POS $(n=20)$, and other plans $(n=14)$, respectively. Only two respondents $(8 \%)$ indicated that their survey responses applied to a portion (eg, a state) of a large national health care plan.

\section{The importance of disease management}

All but one of the 26 respondents reported that DM plays a significant role in their organizations, with seven (27\%) agreeing and 18 $(69 \%)$ strongly agreeing with this statement. The lone exception was "undecided" whether DM plays a significant role in their organization (the two other possible responses were disagree and strongly disagree). One respondent did not answer a question asking how their assessment of DM importance compared to two years ago; of the remaining 25,18 (72\%) said it was a much more important strategy today, five $(20 \%)$ said it was somewhat more important, and two ( $8 \%$ ) said there was no change in its importance (other response options were somewhat less important and much less important).

Respondents were asked to rate the importance of a number of potential benefits of DM programs to their organization's decision to implement DM programs, and were explicitly told that their organization did not have to have demonstrated achievements of these benefits. All 26 respondents considered improving clinical outcomes and reducing medical costs to be either important or very important (Fig. 1). Reducing utilization and improving member satisfaction were rated as important or very important by 23 respondents $(88 \%)$, and supporting marketing to employer customers was considered important or very important by 22 (85\%). Supporting accreditation and improving provider relations received more ratings of moderate or lesser importance.

A separate item on the questionnaire asked respondents to rate the importance of their DM programs to their current and prospective employer customers. Of the 24 respondents who answered this question, nine $(38 \%)$ reported that DM programs were very important, 13 (54\%) important, and two (8\%) somewhat important. No respondents considered their DM programs unimportant or somewhat unimportant to prospective customers.

When asked how often customers had requested proof (such as statistically sound outcomes data) that DM is providing a positive impact on productivity and absenteeism, eight of 25 respondents (32\%) replied that customers often requested proof, 13 (52\%) occasionally, and four $(16 \%)$ never.

\section{Satisfaction with disease management outcomes}

When asked how many discrete DM evaluations their organizations had conducted since 1998, respondents reported a range of 0 to 100 evaluations (mean 8.8). Four respondents (15\%) reported conducting no evaluations; two of these did not answer questions about their overall satisfactions with DM program results. For the 24 respondents who rated the satisfaction of their organizations with DM program results, $75 \%, 71 \%$, and $58 \%$ were satisfied or highly satisfied with clinical results, economic results (eg, utilization changes), and financial results (eg, cost savings), respectively (Fig. 2). More respondents were highly satisfied with clinical results $(46 \%)$ than with economic $(17 \%)$ or financial $(13 \%)$ results. 


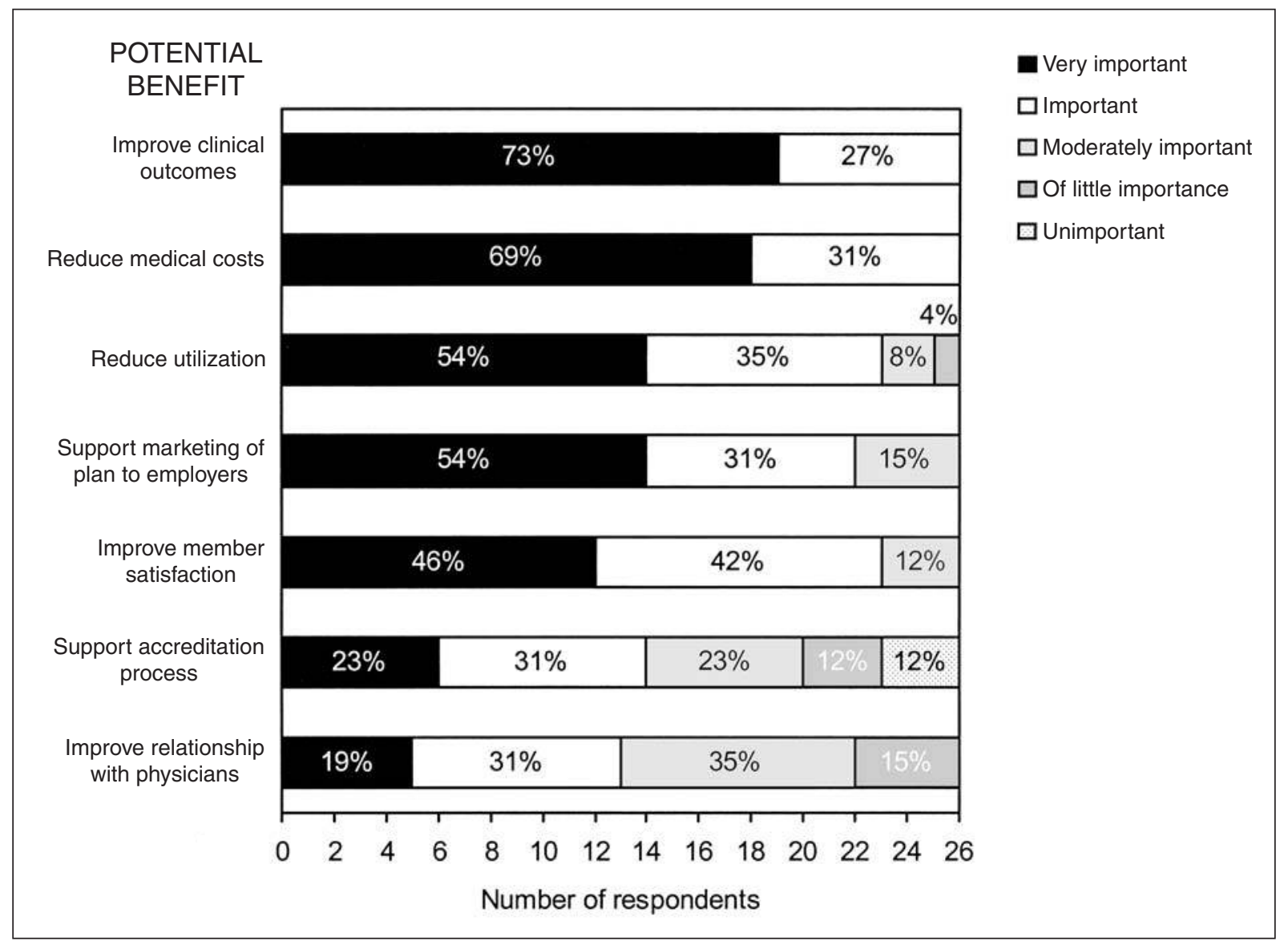

FIG. 1. Importance of potential benefits of disease management (DM) programs to health plan decisions to implement DM programs.

All 26 respondents answered a question regarding how much eight potential barriers had impeded DM program evaluation efforts (Table 1). The three barriers most often cited as having some or considerable impact on program evaluation were time $(65 \%$ of responses), lack of standardized methodology $(62 \%)$, and lack of data (58\%). The three barriers most frequently identified as having no or limited impact were lack of standardized definitions $(62 \%)$, lack of staff experience $(50 \%)$, and insufficient organizational priority $(46 \%)$. In addition to the eight barriers listed on the questionnaire, one respondent wrote that lack of direct contact with members had considerable impact on program evaluation; another wrote that lack of adequate staff and easy-to-use tools had considerable impact.
Detailed results of disease management programs

Twenty-two respondents provided answers to detailed questions about DM programs for specific medical conditions. Each respondent gave results for one to six individual programs (mean 2.7). The questionnaire listed 15 conditions, and respondents could specify others. No respondents gave detailed information about DM programs for the five following conditions listed in the questionnaire: chronic kidney disease, HIV / AIDS, arthritis, lower back pain, and stroke. Table 2 shows summary statistics for the patient populations targeted and enrolled in DM programs for the 10 other listed conditions, plus two specified by respondents.

The method of program evaluation was identified for 52 of the programs considered. The most common evaluation method, used for 26 


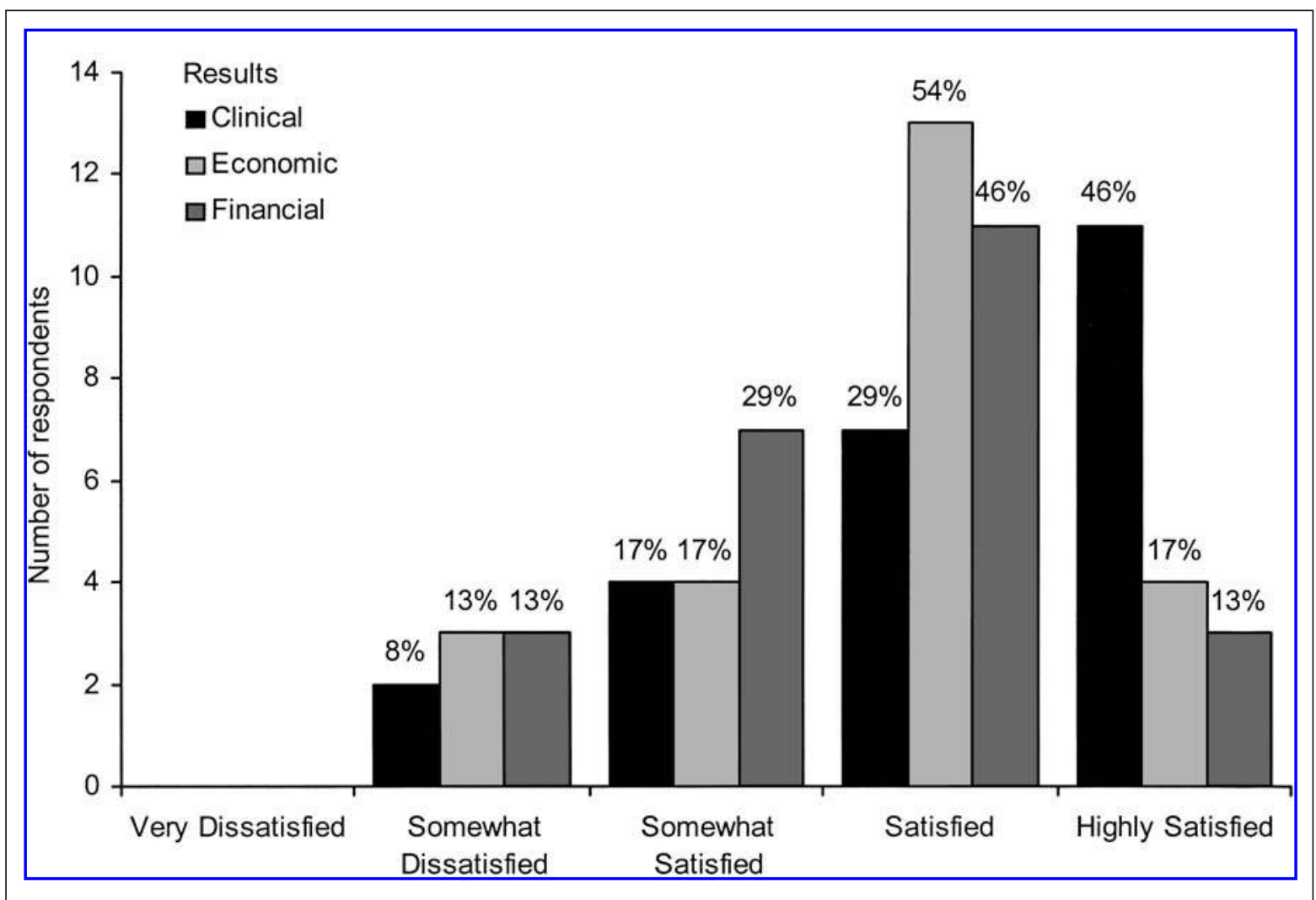

FIG. 2. Satisfaction of health plans with clinical, economic (eg, utilization changes) and financial (eg, cost savings) results of disease management (DM) programs.

programs (50\%), was pre-test/post-test, comparing outcomes for the same members from a previous time period. Comparison of cases and a matched historical control group (different individuals) was used for 16 programs (31\%); nine programs $(17 \%)$ used expected costs calculated from an unmanaged historical control group. Only one program (for rare diseases) was evaluated using a randomized control group, and no programs used a control group of members who had opted out of the program.

Diabetes. The medical condition with the highest number of DM programs in this survey was diabetes, reported by all 26 respondents. Of the 26 diabetes programs, 16 (62\%) were pri-

Table 1. Impact of Potential Barriers to Disease Management Program Evaluation Efforts

\begin{tabular}{lcccc}
\hline & \multicolumn{3}{c}{ Number $(\%$ a) of respondents } \\
\cline { 2 - 5 } Barrier & No impact & Limited impact & Some impact & Considerable impact \\
\hline Lack of data & $7(27)$ & $4(15)$ & $9(35)$ & $6(23)$ \\
Information system & $6(24)$ & $5(20)$ & $11(44)$ & $3(12)$ \\
Lack of standardized definitions & $9(35)$ & $7(27)$ & $8(31)$ & $2(8)$ \\
Lack of standardized methodology & $5(19)$ & $5(19)$ & $12(46)$ & $4(15)$ \\
Lack of staff expertise & $7(27)$ & $6(23)$ & $10(38)$ & $3(12)$ \\
Time & $5(19)$ & $4(15)$ & $8(38)$ & $7(27)$ \\
Insufficient organizational priority & $8(31)$ & $4(15)$ & $7(28)$ & $7(23)$ \\
Cost & $5(20)$ & $6(24)$ & $7(28)$
\end{tabular}

aPercent of responses for each barrier. $n=25$ for Information System and Cost, $n=26$ for all others. 


\begin{tabular}{|c|c|c|c|c|}
\hline & \multirow[b]{2}{*}{$\begin{array}{l}\text { Number of } \\
\text { programs }\end{array}$} & \multicolumn{3}{|c|}{ Mean (n responses) } \\
\hline & & $\begin{array}{l}\text { Members identified } \\
\text { with condition }\end{array}$ & $\begin{array}{c}\text { Members targeted for } \\
\text { enrollment }\end{array}$ & $\begin{array}{c}\text { Members actively } \\
\text { enrolled }\end{array}$ \\
\hline Asthma & 12 & $7,894(12)$ & $4,955(12)$ & $3,933(12)$ \\
\hline $\mathrm{CAD}^{\mathrm{a}}$ & 4 & $13,397(4)$ & $13,397(4)$ & $4,515(3)$ \\
\hline Cancer & 3 & $5,442(3)$ & $3,398(3)$ & $643(3)$ \\
\hline $\mathrm{CHF}$ & 8 & $2,002(8)$ & $1,787(8)$ & $833(8)$ \\
\hline COPD & 3 & $1,325(3)$ & 739 (3) & $330(3)$ \\
\hline Depression & 1 & $15,000(1)$ & $15,000(1)$ & $15,000(1)$ \\
\hline Diabetes & 17 & $15,444(17)$ & $7,491(17)$ & $6,213(17)$ \\
\hline ESRD & 3 & $525(2)$ & $525(2)$ & $277(3)$ \\
\hline High-risk maternity & 3 & $4,511(3)$ & $3,877(3)$ & $2,479(3)$ \\
\hline Rare diseases & 1 & $1,600(1)$ & $1,600(1)$ & $1,200(1)$ \\
\hline \multicolumn{5}{|l|}{ Other } \\
\hline Breast and lung cancer & 1 & $\mathrm{n} / \mathrm{a}$ & $\mathrm{n} / \mathrm{a}$ & $928(1)$ \\
\hline Hyperlipidemia & 1 & $39,398(1)$ & $31,789(1)$ & $31,174(1)$ \\
\hline \multicolumn{5}{|c|}{$\begin{array}{l}\text { aOne respondent furnished limited information on an uncompleted CAD program in addition to full informa- } \\
\text { tion for a completed CAD program. The former is not included here. } \\
\text { CAD, coronary artery disease; } C H F \text {, congestive heart failure; COPD, chronic obstructive pulmonary disease; } \\
\text { ESRD, end-stage renal disease; } n / a \text {, no response given. }\end{array}$} \\
\hline
\end{tabular}

marily built in-house, seven $(27 \%)$ were outsourced, and three (12\%) were assembled using a combination of outsourced tools and inhouse capabilities. For the 19 respondents who specified how long their diabetes programs had been in operation, the average duration was 48 months.

Three respondents indicated ROI for diabetes DM programs of 0.16:1 $(n=864$ enrolled members), 2:1 $(n=24,000)$, and 4:1 $(n=500)$. Weighted by the number of enrollees per plan, the mean ROI was 1.98:1. Eleven respondents gave other summaries of the financial outcomes of their diabetes DM programs, most commonly on a cost per member per month (PMPM) basis. Three diabetes DM programs achieved savings, six experienced increased costs, and two showed no change.

Respondents also provided information on utilization outcomes. Seven reported lower hospitalization rates for enrollees; for the five respondents who specified a percentage decrease, admissions declined between $5 \%$ and $37 \%$. However, the program with ROI of 0.16:1 experienced a $35.4 \%$ increase in inpatient admissions and a $14.8 \%$ increase in emergency room (ER) visits. Four respondents reported fewer ER visits, of whom two provided quantitative results (reductions of $11 \%$ and $27 \%$ ).
Three respondents found no change in ER visits. Another respondent reported that inpatient admissions for all members with diabetes decreased by 266 per 1000 patients, and ER visits by 46 per 1000 over a 12 -month period $(n=$ 14,609 enrolled members).

Clinical outcomes of diabetes DM programs were reported by 13 respondents. These results were characterized by increasing screening rates (seven respondents) and improved clinical measures of blood glucose and lipid control (11 respondents). In addition, four respondents reported various measures of effect of their diabetes DM programs on relations with providers, indicative of high or increased provider satisfaction.

Asthma. After diabetes, asthma was the most frequently cited medical condition for DM programs. Twenty-three respondents offered active asthma programs: 15 developed in-house, six outsourced, and two assembled from inhouse and outsourced components. The average duration of asthma DM programs was 38 months for the 18 respondents who reported how long their program had been in operation.

Two respondents specified an ROI for their asthma program (2.5:1 and $3.5: 1 ; n=1071$ and 65 enrollees, respectively). Weighted by 
number of enrollees per plan, mean ROI was 2.56:1. Eight respondents reported other financial outcomes, with five describing decreased costs and three reporting increased costs.

Utilization outcomes for asthma DM programs were generally promising, with eight respondents describing decreased hospital and ER utilization, and two respondents reporting no change. For programs with quantified utilization decreases, hospital admissions declined by between $3 \%$ and $100 \%(n=5$ responses) and ED visits decreased by between $5 \%$ and $87.5 \%(n=5)$.

Clinical outcomes were largely positive, with improvement in appropriate use of asthma medications reported by seven respondents, decrease in patients with uncontrolled asthma by one respondent, and decreased days missed from work by another. One program did not show a change in prevalence of asthma medication use. Three respondents indicated high or increased provider satisfaction.

Other diseases. Because fewer than 10 respondents provided detailed information for DM programs for each of the other medical conditions, in-depth descriptions of the survey results are not provided here for these conditions. As summarized in Table 3, positive outcomes were reported for at least some DM programs for most diseases.
Improvement and future directions of disease

management programs

Most respondents who answered how they saw their organization's investment in DM changing over the next three years anticipated that it would increase (21 of 24 respondents; $88 \%)$; three $(13 \%)$ reported that they did not know the direction of future DM investment. No respondents anticipated decreasing DM investment. Considering DM programs not yet offered, the three highest priority DM programs for respondents' organizations to develop and implement in future were for lower back pain, CAD, and depression.

Another section of the questionnaire asked which of six Internet applications health plans already used in DM programs and which they intended to implement over the next 2 years. The questionnaire did not have a separate option for "do not intend to implement," so no answer was taken to signify no intention to implement. Figure 3 shows that online patient reminders, online health risk assessments, and Web-based patient education were most often identified for future implementation. Considering both current offerings and future implementation, the most prevalent applications were Web-based patient education, online health risk assessments, and Web-based clinical guidelines. Health plans that already used Internet applications did not experience high satisfaction with these tools; mean scores for

Table 3. Outcomes of Disease Management Programs for Nine Medical Conditions

\begin{tabular}{|c|c|c|c|c|c|}
\hline \multirow[b]{2}{*}{ Condition } & \multicolumn{5}{|c|}{ No. of respondents reporting positive outcomes $\mathrm{a} /$ no. reporting detailed outcomes results } \\
\hline & ROI & Financial & Utilization & Clinical & Provider relations \\
\hline CAD & $2 / 2$ & $2 / 4$ & $1 / 1$ & $4 / 4$ & $1 / 1$ \\
\hline Cancer & $2 / 2$ & $2 / 2$ & $1 / 1$ & $\mathrm{n} / \mathrm{a}$ & $\mathrm{n} / \mathrm{a}$ \\
\hline $\mathrm{CHF}$ & $3 / 3$ & $4 / 7$ & $4 / 5$ & $3 / 3$ & $1 / 1$ \\
\hline COPD & $\mathrm{n} / \mathrm{a}$ & $1 / 1$ & $\mathrm{n} / \mathrm{a}$ & $1 / 1$ & $1 / 1$ \\
\hline Depression & $\mathrm{n} / \mathrm{a}$ & $\mathrm{n} / \mathrm{a}$ & $\mathrm{n} / \mathrm{a}$ & $0 / 1$ & $\mathrm{n} / \mathrm{a}$ \\
\hline ESRD & $0 / 2$ & $2 / 2$ & $1 / 2$ & $1 / 1$ & $0 / 1$ \\
\hline High-risk maternity & $\mathrm{n} / \mathrm{a}$ & $1 / 1$ & $2 / 3$ & $2 / 2$ & $\mathrm{n} / \mathrm{a}$ \\
\hline Hyperlipidemia & $\mathrm{n} / \mathrm{a}$ & $\mathrm{n} / \mathrm{a}$ & $1 / 1$ & $1 / 1$ & $\mathrm{n} / \mathrm{a}$ \\
\hline Rare diseases & $1 / 1$ & $1 / 1$ & $\mathrm{n} / \mathrm{a}$ & $\mathrm{n} / \mathrm{a}$ & $\mathrm{n} / \mathrm{a}$ \\
\hline
\end{tabular}

aRemaining respondents reported no improvement or negative outcomes.

ROI, return on investment; $\mathrm{CAD}$, coronary artery disease; $\mathrm{CHF}$, congestive heart failure; COPD, chronic obstructive pulmonary disease; ESRD, end-stage renal disease; $\mathrm{n} / \mathrm{a}$, not measured or no response given. 


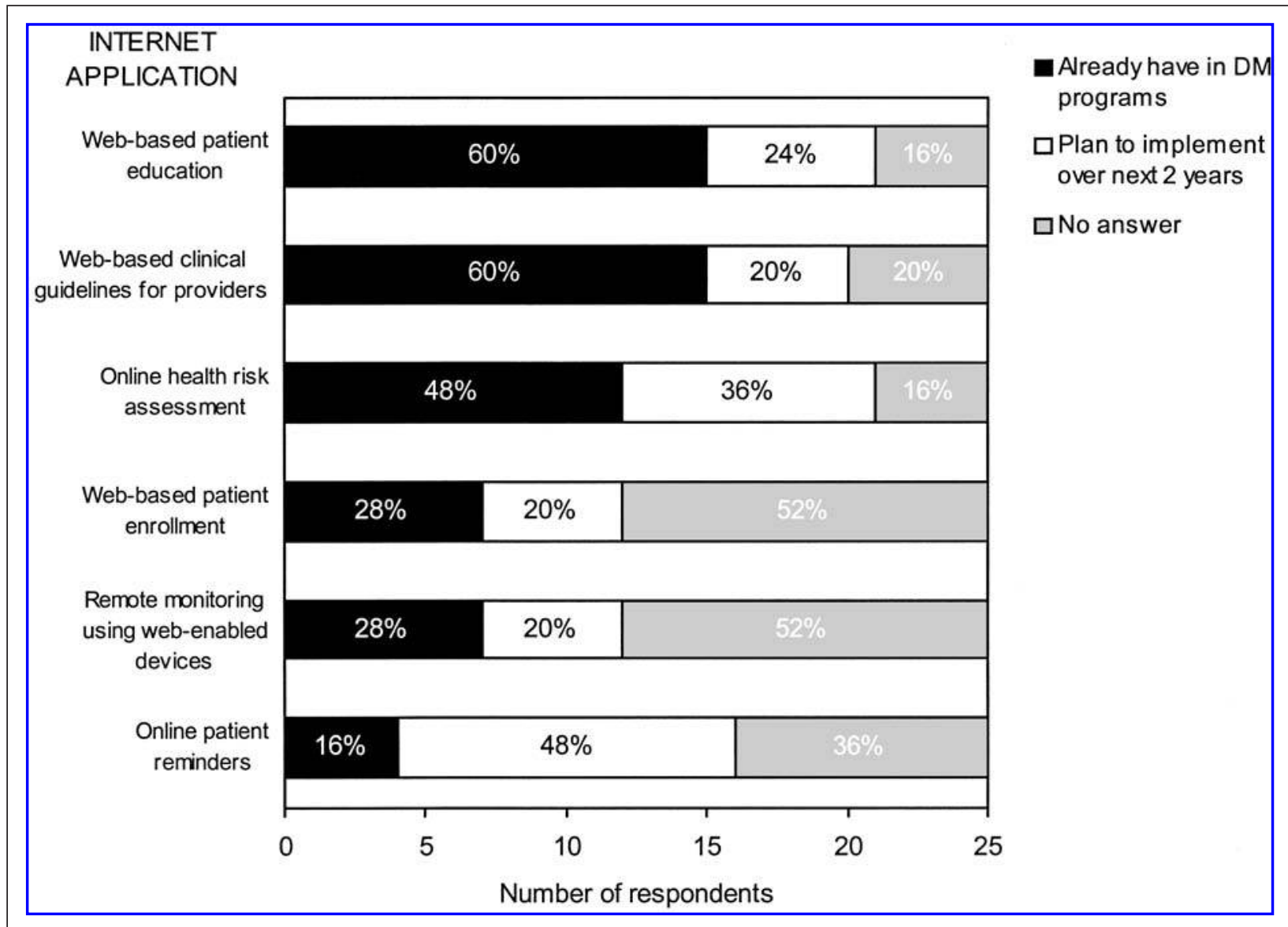

FIG. 3. Current and future implementation of Internet applications for disease management (DM) programs by health plans.

satisfaction with these six applications ranged from 2.4 (for online patient reminders) to 3.7 (remote monitoring) on a scale from 1 (not satisfied) to 5 (very satisfied).

Respondents were asked to rate the importance of each of 10 potential barriers to expanding DM programs in the future; $23-25$ responses were obtained for each barrier. The three obstacles most frequently identified as being important or very important were limited financial resources to invest in DM (17 of 25 responses; $68 \%$ ), lack of demonstrated clinical and/or financial outcomes (14/25; 56\%), and lack of patient interest in participation or follow through $(13 / 25 ; 52 \%)$. The three barriers most often identified as being unimportant or of little importance were lack of demand from employers $(16 / 25 ; 64 \%)$, HIPAA requirements $(14 / 24 ; 58 \%)$, and difficulty managing multiple vendors $(13 / 23 ; 57 \%)$. The remaining barriers were more often rated as moderately important: insufficient information, lack of physician support or "buy-in," suboptimal support from senior management, and difficulty coordinating multiple programs.

\section{DISCUSSION}

Ability to draw general conclusions from the results of the Disease Management Outcomes Consolidation Survey is weakened by several limitations. Chief among these is the low response rate to the survey (less than 10\%), resulting in low sample size. Some contacts stated that they would not provide results without financial compensation (which was not available), and others indicated unwillingness to make the requested information public. An original objective of the survey was to fa- 
cilitate benchmarking of DM programs, and some organizations may have chosen not to participate because they did not wish to be benchmarked. In addition, the length and complexity of the survey probably dissuaded several targeted contacts. Although the cover letter to the survey stated that it should take less than an hour to complete once the necessary information was assembled, assembling that information may have been prohibitively timeconsuming for many. Contacts who did complete and return the survey may have had information more readily accessible, which would introduce nonresponse bias if this correlated with better program management (ie, respondents may have had more successful programs than the average health plan).

In combination with low questionnaire response rate, few items were answered by all respondents, further reducing the number of data points and preventing definitive conclusions from being reached in many areas. This is particularly true for the detailed evaluations of DM program effectiveness, exacerbated by the difficulty of comparing the "free form" text answers in this section of the survey. The effectiveness section also did not capture possible reasons for the outcomes reported (eg, why inpatient admissions increased with one diabetes DM program). Comparison of results from different respondents would likely have been facilitated by a more simplified and restrictive survey instrument. ${ }^{8}$

Nevertheless, valuable information was obtained reflecting the experience of health plans covering more than 14 million commercial members, with over 230,000 enrollees in 57 DM programs. Some strong themes emerged from the survey results, including the significant and increasing role that DM programs play in the respondents' organizations. Most respondents anticipated increasing investment in DM in the future, which is consistent with the reported importance of their DM programs to employer customers. However, just as analysis of survey results was hampered by differences in the types of outcomes measured and reported by respondents, respondents also identified lack of standardized methodology as a major barrier to their in-house program evaluations. This constitutes a problem for commercial health plans; most respondents indicated that customers at least occasionally request proof of the financial benefit of their programs. Differences in outcome measurements impair the ability of health plans to benchmark the performance of their DM programs against others. These findings support calls for work and consensus on a standardized framework for evaluating outcomes of DM programs. ${ }^{1,9}$

Improving clinical outcomes appeared to be the highest priority for DM programs, considered very important by more survey respondents than either cost or utilization control. This result indicates industry accord with the first guiding principle of the American Heart Association's policy recommendations for DM, namely that its main goal should be to improve quality of care and patient outcomes, emphasizing the overall benefits derived from DM rather than only reduced health care expenditures. ${ }^{9}$ Other authors have echoed the principle that the rationale for DM programs should be based on their effectiveness and value, like other medical interventions. ${ }^{10}$

One proposed method to measure the overall value of different DM programs and compare them with other medical interventions is to express clinical benefit in terms of qualityadjusted life-years (QALYs), allowing calculation of cost-utility ratios (ie, cost per QALY). ${ }^{11,12}$ For example, a meta-analysis of randomized controlled trials (RCTs) of DM programs for depression reported cost-utility ratios between \$9051/QALY and $\$ 49,500 /$ QALY, ${ }^{13}$ below the threshold of $\$ 50,000 /$ QALY that has been frequently cited since 1982 as acceptably cost-effective, and highly cost-effective by today's standards. ${ }^{14}$ However, costutility analysis has not yet achieved the prominence in DM that it has in other branches of medical outcomes research.

Indeed, for commercial health plans that must justify their DM programs to customers, ROI remains a key metric despite methodological criticisms leveled against it. ${ }^{15,16}$ Of the five ROI values provided by survey respondents for diabetes and asthma programs, four indicated cost savings of similar magnitude to ROI for DM programs targeting these conditions reported in the recent literature, ${ }^{17-19}$ but one suggested increased costs. Given the diversity of 
patient populations, program designs and analytical methods used by responding health plans, such variation in financial results is not unexpected. Future efforts should focus on identifying what factors (eg, time since implementation) most strongly predict why some DM programs show cost savings while others increase expenditures.

Only one responding health plan reported using the "gold standard" RCT design to evaluate its DM program. Because of its convenience, it is not surprising that the pre-post design was most often employed. However, this method is not as scientifically rigorous as those that use randomization or control groups. ${ }^{20,21}$ The DMAA's Consensus Statement on assessing DM outcomes recommends randomized controlled designs whenever possible; when this is not practical, a control group is preferable to a pre-post design. ${ }^{22}$ Use of the next most frequently reported method, historical controls, has the advantage of reducing the problem of regression to the mean ${ }^{15}$; however, it remains susceptible to changes in external factors unrelated to DM program effects. ${ }^{20}$ The $\mathrm{CBO}$ critique of the financial benefit of DM programs highlighted the limitations of outcomes comparators other than randomized control groups. ${ }^{4}$ More widespread use of RCTs such as the "Women Take PRIDE" DM program, which conservatively estimated that savings exceeded program costs by $5: 1$ for patients with heart disease, ${ }^{23}$ would presumably go a long way to addressing CBO concerns (this study was apparently not considered in the $\mathrm{CBO}$ review).

Non-outcomes results of the Disease Management Outcomes Consolidation Survey also were informative. Although satisfaction with Internet-based applications was moderate, many respondents planned to add more of these tools in the near future. This finding supports predictions that the use of information management technologies in DM programs will continue to grow. ${ }^{24,25}$ Additional research is warranted to quantify the costs and benefits of these tools.

Ongoing Medicare DM demonstration projects are expected to provide considerable data on the financial, utilization and clinical benefits of DM programs. ${ }^{26}$ Reduced utilization al- ready has been demonstrated to offset program costs in a RCT of a multi-disease DM program for Medicare Plus Choice enrollees. ${ }^{27}$ There is great scope, however, for commercial health plans to contribute valid evidence that can be compared among DM programs by heeding recommendations of recently issued guidelines when they conduct program evaluations. ${ }^{12,20-22,28}$

\section{ACKNOWLEDGMENTS}

We wish to thank Anne Fisher and Linda Schairer of Thomson Medstat. This study was made possible by support from the Disease Management Association of America and grants from AstraZeneca, Health Dialog Services Corporation, Matria Healthcare, and Applied Health Outcomes/GSK.

\section{REFERENCES}

1. Villagra V. Strategies to control costs and quality: a focus on outcomes research for disease management. Med Care 2004;42:III24-III30.

2. Casalino LP. Disease management and the organization of physician practice. IAMA 2005;293:485-488.

3. Ofman JJ, Badamgarav E, Henning JM, et al. Does disease management improve clinical and economic outcomes in patients with chronic diseases? A systematic review. Am J Med 2004;117:182-192.

4. Congressional Budget Office. An analysis of the literature on disease management programs. Washington, DC: Congressional Budget Office, 2004 Oct 13.

5. Nash DB. An open letter to the disease management community. Dis Manag 2004;7:265-266.

6. Kozma CM. Does disease management reduce health care costs? Manag Care Interface 2004;17:42-43.

7. Maljanian R, Bohannon R. Disease Management Outcomes Consolidation Project: review of published and unpublished results. Washington, DC: Strategic Health Equations, LLC for Disease Management Association of America, 2005.

8. Haffer SC. Using multiple survey vendors to collect health outcomes information: how accurate are the data? Health Qual Life Outcomes 2003;1:6.

9. Faxon DP, Schwamm LH, Pasternak RC, et al. Improving quality of care through disease management: principles and recommendations from the American Heart Association's Expert Panel on Disease Management. Circulation 2004;109:2651-2654.

10. Fireman B, Bartlett J, Selby J. Can disease management reduce health care costs by improving quality? Health Aff (Millwood) 2004;23:63-75. 
11. Selby JV, Scanlon D, Lafata JE, Villagra V, Beich J, Salber PR. Determining the value of disease management programs. Jt Comm J Qual Saf 2003;29:491-499.

12. Wilson T, MacDowell M. Framework for assessing causality in disease management programs: principles. Dis Manag 2003;6:143-158.

13. Neumeyer-Gromen A, Lampert T, Stark K, Kallischnigg G. Disease management programs for depression: a systematic review and meta-analysis of randomized controlled trials. Med Care 2004;42:1211-1221.

14. Eichler HG, Kong SX, Gerth WC, Mavros P, Jonsson B. Use of cost-effectiveness analysis in health-care resource allocation decision-making: how are cost-effectiveness thresholds expected to emerge? Value Health 2004;7:518-528.

15. Fetterolf D, Wennberg D, Devries A. Estimating the return on investment in disease management programs using a pre-post analysis. Dis Manag 2004;7:5-23.

16. Duncan I. It's time for the industry to move on from ROI. Dis Manag 2004;7:159-160.

17. Cousins MS, Liu Y. Cost savings for a preferred provider organization population with multi-condition disease management: evaluating program impact using predictive modeling with a control group. $\underline{\text { Dis }}$ Manag 2003;6:207-217.

18. Snyder JW, Malaskovitz J, Griego J, Persson J, Flatt K. Quality improvement and cost reduction realized by a purchaser through diabetes disease management. Dis Manag 2003;6:233-241.

19. Tinkelman D, Wilson S. Asthma disease management: regression to the mean or better? Am J Manag Care 2004;10:948-954.

20. Standard outcome metrics and evaluation methodology for disease management programs. American Healthways and Johns Hopkins Consensus Conference. Dis Manag 2003;6:121-138.

21. Linden A, Roberts N. A user's guide to the disease management literature: recommendations for report- ing and assessing program outcomes. Am J Manag Care 2005;11:113-120.

22. Fitzner K, Sidorov J, Fetterolf D, et al. Principles for assessing disease management outcomes. Dis Manag 2004;7:191-201.

23. Wheeler JR. Can a disease self-management program reduce health care costs? The case of older women with heart disease. Med Care 2003;41: 706-715.

24. Nobel JJ, Norman GK. Emerging information management technologies and the future of disease management. Dis Manag 2003;6:219-231.

25. Crosson FJ, Madvig P. Does population management of chronic disease lead to lower costs of care? Health Aff (Millwood) 2004;23:76-78.

26. Foote SM. Population-based disease management under fee-for-service Medicare. Health Aff (Millwood) 2003;Suppl Web Exclusives:342-356.

27. Martin DC, Berger ML, Anstatt DT, et al. A randomized controlled open trial of population-based disease and case management in a medicare plus choice health maintenance organization. Prev Chronic Dis 2004;1:A05-A11.

28. Wilson TW, Gruen J, William T, et al. Assessing return on investment of defined-population disease management interventions. It Comm J Qual Saf 2004;30:614-621.

Address reprint requests to: Karen Fitzner, Ph.D.

Disease Management Association of America 601 Pennsylvania Ave., N.W. Suite 500, South Building Washington, DC 20004

E-mail:kfitzner@dmaa.org 
This article has been cited by:

1. Kenneth Patric, Joyce D. Stickles, Robin S. Turpin, Jeffrey B. Simmons , James Jackson, Elizabeth Bridges , Manan Shah . 2006. Diabetes Disease Management in Medicaid Managed Care: A Program EvaluationDiabetes Disease Management in Medicaid Managed Care: A Program Evaluation. Disease Management 9:3, 144-156. [Abstract] [PDF] [PDF Plus]

2. Wendy D. Lynch, Chin-Yu Chen, Joel Bender, Dee W. Edington. 2006. Documenting Participation in an Employer-Sponsored Disease Management Program: Selection, Exclusion, Attrition, and Active Engagement as Possible Metrics. Journal of Occupational and Environmental Medicine 48:5, 447-454. [CrossRef]

3. Karen A. Fitzner, Cynthia Gómez, Heather Chappell . 2005. DMAA Quality and Research InitiativeDMAA Quality and Research Initiative. Disease Management 8:6, 392-396. [Citation] [PDF] [PDF Plus] 